\title{
A multi-scale analysis of settlement density and pattern dynamics of the barnacle Semibalanus balanoides
}

\author{
Jeremy M. Hills*, Jeremy C. Thomason \\ University Marine Biological Station Millport, Isle of Cumbrae KA28 0EG, Scotland, UK
}

\begin{abstract}
Settlement pattern and density of Semibalanus balanoides (L.) in the Clyde estuary were studied on wood, concrete, steel and sandstone rock during 1994. The position of each newly metamorphosed juvenile barnacle was mapped to the nearest $1 \mathrm{~mm}$ over the course of 75 tides. The total number of settled barnacles on the surfaces varied between 0 and $24.09 \mathrm{~cm}^{-2}$ The tide number at which $50 \%$ of the total number of barnacles had settled on each surface varied between tide 23 and tide 44. A new measure describing surface roughness in relation to $S$. balanoides settlement using data on cyprid morphology and behaviour was devised; this index was termed Potential Settling Sites (PSS). The number of PSS for 2-dimensional profiles of each of the surfaces, using accurate replicas and a magnified photo mosaic, was measured. For the surfaces the total number of settlers was best related to the index PSS $\min$ [Settler Density $\left.=\left(5.68 \times \mathrm{PS}_{\min }\right)-4.16 ; \mathrm{p}<0.01\right]$. Two other measures of surface roughness, ISO number, a standard engineering measure of surface relief, and fractal dimensions, were not related to settler density. Settlement pattern was found to vary with settlement density and spatial scale of analysis. A multi-scale analysis using Morisita's index suggested that $S$. balanoides were generally settling aggregatedly at low densities $\left(<8 \mathrm{~cm}^{-2}\right)$, with strongest aggregations at approximately $30 \mathrm{~mm}$ block sizes; it is proposed that this was related to the scale of the close exploration behaviour of the cyprid. Settlement at higher densities $\left(>8 \mathrm{~cm}^{-2}\right)$ tended to be random. Aggregated settlement at low densities could be related to the requirement to find a mate in close proximity, whereas avoidance of aggregated settlement by $S$. balanoides at higher densities could potentially be an intraspecific competition avoidance technique. Nearest neighbour analysis at low settlement densities $(0.5$ to $1.75 \mathrm{~cm}^{-2}$ ) found that cyprids settled aggregatedly to at least the first nearest neighbour; it is proposed that this is related to small-scale gregarious settlement behaviour
\end{abstract}

KEY WORDS: Barnacle $\cdot$ Semibalanus balanoides S Settlement Roughness · Texture $\cdot$ Contour $\cdot$ Substratum $\cdot$ Fractal

\section{INTRODUCTION}

Larval settlement of sessile marine invertebrates has been widely studied because of the importance of the process to the future growth, survival, and reproductive success of the adult. In many balanomorph barnacle species, the site on which the cyprid larva settles is related to 2 general processes. Firstly, the cyprid larvae are carried by oceanic currents and more local tidal movements $;$ this determines the locality of the surfaces

•E-mail:gbfa16@udcf.gla.ac.uk onto which the larvae can settle. Secondly, the barnacle samples a set of local sites until a suitable substratum is detected; the settlement process is then initiated.

Larval supply to a locality has been found to determine the density of settling barnacles. Minichinton \& Scheibling (1993), studying Semibalanus balanoides (L.), found that there was a strong correlation between cyprid availability and settler density over a range of tidal heights and concluded that near-shore hydrodynamics may determine local settlement patterns of sessile marine invertebrates with planktonic life stages. Similarly, Gaines et al. (1985) and Bingham (1992) 
found that spatial variation in settlement of Balanus glandula and $B$. eburneus, respectively, reflected the spatial distribution of cyprid concentration in the water column. Hurlburt (1991) noted that patterns of larval settlement, even among co-occurring related species, tend to be species-specific.

Limited settlement time windows (Anderson 1994) and potentially poor swimming ability in relation to near-shore hydrodynamics suggest that barnacles have only a limited degree of choice on the locality in which they can settle on a large scale. At scales $\leq 100 \mathrm{~m}$. Pineda (1994) found that spatial variation along the shore in Chthalamus spp. and Pollicipes polymerus was related to behavioural phenomena, substratum variability and possibly micro-hydrodynamic phenomena; consequently, active site selection probably becomes more important at a scale of $\leq 100 \mathrm{~m}$ in barnacles. Relationships between barnacle settlement density, at scales $\leq 100 \mathrm{~m}$, and surface characteristics have been widely documented in relation to physical characteristics such as shore level (Raimondi 1990), water flow (Mullineaux \& Butman 1991), illumination and colour of substratum and temperature (Konya \& Miki 1994) and biological characteristics such as free space on the substratum (Minchiton \& Scheibling 1993), algal cover (Le Tourneux \& Bourget 1988, Minchiton \& Scheibling 1993) and biofilm development (Maki et al. 1988, Henschel \& Cook 1990).

One further physical property of the surface considered important to the settlement of the barnacle is surface roughness. Surface roughness can be differentiated into surface texture (scales of substratum heterogeneity below the size of the larvae) and surface contour (scales of substratum heterogeneity larger than the size of the larvae) (Le Tourneux \& Bourget 1988). This terminology will be used in the present study.

The preference of Semibalanus balanoides for settling in cracks and pits was well documented by Crisp \& Barnes (1954) and Crisp (1961). Recently, Le Tourneux \& Bourget (1988) found, employing fractal geometry, that $S$. balanoides could discriminate between surface textures below a step-size of $35 \mu \mathrm{m}$, while Wethey (1984) concluded that surface contour is by far the dominant influence on settlement density in $S$. balanoides. Evidence thus implicates both surface contour and texture as important variables determining settlement density in the field for $S$. balanoides.

Another important influence on cyprid settlement is the presence of previously settled conspecifics (KnightJones 1953). Fragments of various parts of the barnacles' bodies (Knight-Jones 1953), removed barnacle bases (Knight-Jones 1953, Crisp 1961, cf. Wethey 1984) and extracts from conspecifics (Crisp \& Meadows 1962, Larman \& Gabbot 1975, Dinnen \& Hines 1994), congenerics (Knight-Jones 1955, Dinnen \&
Hines 1994) and other marine organisms (Larman \& Gabbot 1975) have been shown to enhance settlement.

Crisp (1961) found that Sembibalanus balanoides settlement leads to a behavioural pattern akin to territoriality in non-sessile organisms, in that settlement leads to a zone of spatial separation beyond the extremities of the cyprid's body. The process which creates the pattern of 'territoriality' in sessile animals differs from those characteristics of mobile animals in that, for sessile animals, the process is a 1-way interaction (settled barnacle to settling cyprid) and represents a single irreversible event (i.e. the settlement process). Such gregarious teritorial settling behaviour can lead to formation of clear spatial patterns over time (Wethey 1984). Satchell \& Farrell (1993) compared the settlement pattern of 4 species of barnacles (Balanus amphitrite, B. glandula, Chthalamus dalli and Pollicipes polymerus) with density. In the 3 balanomorph species no relationship between aggregation and settler density was apparent; however, in $P$. polymerus aggregation at higher densities was found.

The approximate spatial scales over which a set of factors affects barnacle settlement patterns can be represented schematically (Fig. 1). A distinction is made between those settlement factors over which the larvae has active control and those factors for which the cyprid is passive. Active control is related to the cyprid's motility. It has been shown for Semibalanus balanoides that 3 scales of active behaviour can be

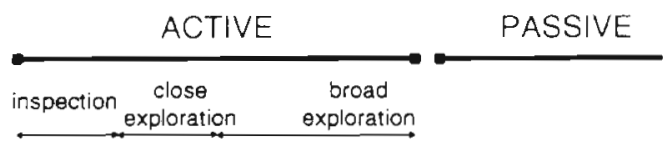

Oceanic \&

tidal features

Local

hydrodynamic

features

Physio-

chemical \&

biological

characteristics

\section{Conspecific}

density

Neighbourhood effects

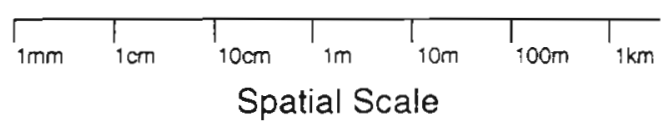

Fig. 1 Schematic diagram of the settlement processes for Semibalanus balanoides showing the approximate spatial scale of areas of active and passive control over settlement, some of the important cues to settlement, and 3 scales of settlement behaviour 
identified (Knight-Jones \& Crisp 1953, Crisp 1961): (1) broad exploration -- the larva follows a relatively straight path over a substratum and possibly swims off to another substratum; (2) close exploration - consists of relatively short steps in a variable direction while the cyprid uses the antennules to test the substratumi (3) inspection - consists of movement at a scale not much greater than the cyprid's body length involving rotation and to-and-fro movements.

Evidence for the precise spatial scale over which the 3 types of settling behaviour operate in Semibalanus balanoides is not clear from the literature. Le Tourneux \& Bourget (1988) estimated the spatial scales of the 3 types of active selection behaviour in $S$. balanoides to correspond roughly to $1 \mathrm{~m}, 1 \mathrm{~mm}$ and $<300 \mu \mathrm{m}$ for broad exploration, close exploration and inspection, respectively. Mullineaux \& Butman (1991) found, for Balanus amphitrite cyprids settling in flow regimes, that the net excursion of cyprids was generally $<3 \mathrm{~cm}$.

The general approach of the work presented here was not to control all aspects of natural variation affecting Semibalanus balanoides settlement, but rather to determine generalisations of settlement density on a variety of natural surfaces. The 7 sites used in this study were no more than $5 \mathrm{~m}$ apart, and so fell well within the zone of active site selection (Fig. 1 this study; Pineda 1994).

The aims of the study were: firstly, to identify which characteristics of surface roughness determine density of Semibalanus balanoides cyprid settlement; secondly, to carry out a multi-scale analysis of barnacle spatial settlement patterns; and thirdly, to relate the scales of settlement pattern to cyprid behaviour.

\section{MATERIALS AND METHODS}

Study site and natural surfaces. This study was carried out near Keppel Pier at the University Marine Biological Station, Greater Cumbrae, Scotland, UK. Keppel Pier is situated in the Largs/Fairlie channel of the Clyde estuary. The study took place in the spring of 1994, starting after heavy barnacle settlement had commenced on natural surfaces.

Seven surfaces were used in this study (Table 1). Five surfaces were already situated at the base of the pier; these were made from the island's bare rock (old red sandstone), concrete and wood. All these surfaces were over 100 yr old and appeared relatively homogeneous in terms of surface roughness and colour to visual inspection. Two further surfaces were introduced to the study area; these 2 surfaces were found as flotsam on the shoreline of the Isle of Cumbrae and were both made of mild carbon steel - one was enamelled the other was rusty. These 2 surfaces were securely fastened onto wooden posts located at the site. All surfaces were at least $50 \times 50 \mathrm{~cm}$. The surfaces were medially placed within the local Semibalanus balanoides settlement zone. All the surfaces had barnacle settlement from the 1994 season upon them, and it was thus considered that these surfaces represented a range of possible settling surfaces for barnacles. Differences between the surfaces included texture, surface chemistry, orientation and colour.

On each of the surfaces a central $10 \times 10 \mathrm{~cm}$ quadrat was permanently marked at each corner using a small indentation from a chisel. All the quadrats were cleaned during the low tide prior to the start of the experiment using a chisel followed by thorough washing with wire and bristle scrubbing brushes and seawater. All visual signs of previously settled barnacles and other species were removed.

Collection of settlement data. Cyprids - potential settlers: A total of five 20 min tows were made by the RV 'Aplysia' in the Largs/Fairlie Channel for cyprid larvae. The tows used a medium plankton net (mesh aperture size $335 \mu \mathrm{m}$ ) pulled at 2 knots, $1 \mathrm{~m}$ below the surface. One tow was carried out prior to the main study period, 3 tows during and 1 after the main study period.

The contents of the tows were preserved in $4 \%$ seawater formalin. Cyprids in five $15 \mathrm{ml}$ sub-samples were counted and the total number of cyprids per tow was calculated by multiplying the mean of the counted subsamples by the volume of the tow contents.

Barnacles - settlers: Each of the 7 quadrats was photographed a number of times during a low tide using a $35 \mathrm{~mm}$ SLR camera with a $50 \mathrm{~mm}$ lens and colour transparency film (Kodak-Ektachrome, ASA 200). A flash was used if ambient light conditions were too low.

The settlement experiment commenced on the afternoon of 13 May 1994 (tide $=0$ ) and continued for 75 tides until the early morning of 21 June 1994 (tide 75). A total of 22 pictures were taken of each quadrat at low

Table 1. List of the 7 surfaces studied with a description of the substratum, the number of Semibalanus balanoides settled after 75 tides and the estimated tide number at which $50 \%$ of the barnacles settled

\begin{tabular}{|clcc|}
\hline $\begin{array}{c}\text { Surface } \\
\text { no. }\end{array}$ & $\begin{array}{l}\text { Surface } \\
\text { description }\end{array}$ & $\begin{array}{c}\text { Total no. settled } \\
\text { over 75 tides }\end{array}$ & $\begin{array}{c}\text { Tide at which } \\
50 \% \text { settled }\end{array}$ \\
\hline 1 & Concrete & 2409 & 23 \\
2 & Enamelled metal & 0 & - \\
3 & Wood post & 837 & 40 \\
4 & Rusty metal & 656 & 30 \\
5 & Wood post & 1565 & 44 \\
6 & Concrete & 1247 & 34 \\
7 & Sandstone rock & 1822 & 32 \\
& & & \\
\hline
\end{tabular}


tide; these were at tide numbers $3,4,5,6,7,8,9,10,11$, $12,14,16,20,25,28,33,41,47,54,60,69$ and 75 .

This study was concerned with the settlement of barnacles; thus, only those individual cyprids which had settled and metamorphosed into barnacles were recorded and used in the analyses. To map the position of barnacles each photograph was displayed using a slide-projector so that the $10 \times 10 \mathrm{~cm}$ quadrat fitted into a twice life-size paper grid divided into $100 \times 100$ squares. The position of the centre of each cyprid that had metamorphosed into a barnacle (i.e. settled) was drawn onto the paper grid and the $x$ and $y$ coordinates recorded to the nearest millimetre.

Post-settlement mortality was not quantitatively recorded during the course of this study. However, from frequent observation of the surfaces during the course of the experiment and subsequent mapping of the settled barnacles, little post-settlement mortality was observed. It was thus assumed to be occurring relatively rarely and of little significance to the overall settlement density and pattern.

Analysis of surface roughness. After the end of the experiment at tide 75 each quadrat was again cleaned as befare. A dental impression material, polyvinylsiloxane (Kerr Manufacturing Co., Romulus, MI, USA), was used to replicate the surface of the quadrats. This substance has an accuracy of replication of $\sim 1 \mu \mathrm{m}$ (Marrs et al. 1995). A positive cast of the replica was made with epoxy adhesive (Ciba-Geigy). Two $1 \mathrm{~cm}$ wide slices were taken from each cast using a mineralogist's diamond lapping saw. The slices were taken at approximately 2.5 and $7.5 \mathrm{~cm}$ along the horizontal $(x)$ axis. A set of 10 overlapping print photographs of the profile of the casts slices were taken under a dissecting microscope at $10 \times$ magnification; each photograph had a field of view of approximately $10 \mathrm{~mm}$. The prints were joined together to make a single photo mosaic of the surface profile.

Three methods for estimating the surface roughness were used: the ISO number (a standard engineering measure of surface relief), the number of 'potential settling sites' and the fractal dimension.

ISO number: The ISO number was determined from the profile heights measured from the photo mosaic. The ISO number was calculated by determining the mid-point between the minimum and maximum profile values (over $10 \mathrm{~cm}$ ), and then the mean of the 5 highest and 5 lowest values from the mid-point was calculated. The ISO number represents a measure of the total surface relief.

Potential settling sites: The number of potential settling sites (PSS), an estimate representing the number of sites available for settlement as determined by surface roughness, was calculated for each profile using the following technique. A cyprid was graphically summarised using a functional morpho-ethological symbol. To construct the symbol accurately, the length of 20 cyprids was measured using a light microscope fitted with a calibrated ocular graticule. A straight line was drawn on a clear acetate sheet to represent the mean length of a cyprid (mean length $=0.99 \mathrm{~mm}, \mathrm{SE}=$ $0.178 \mathrm{~mm}$ ) at the same magnification as the photo mosaic: the 2 ends of this base line were connected with a semi-circle. A further extension line half the length of the cyprid was drawn from either end of the base line in the same plane. Two identical symbols were made on separate acetate strips.

The number of PSS for each surface was determined by moving a cyprid symbol along the mosaic of the surface profile. An a priori decision was made that a PSS was a position on the profile surface where the barnacle symbol was arranged at its most stable point on the surface such that at least 1 of its extension lines was overlapping the surface and neither of its extensions were overlapping with the extensions from the symbol in the neighbouring PSS. These rules do not take into account the reproductive requirements of a hermaphroditic barnacle. Examples of this morpho-ethological symbol and PSS are given in Fig. 2.

The extensions on the representation of the cyprid body have 2 major constraints for the number of PSS on a surface profile. Firstly, cyprids can only be packed on the surface with a certain segregation distance between them, in this case 1 body length. This inhibition of close packing has been previously described by Crisp (1961). Secondly, PSS must have a change of gradient for the extensions to overlap the surface, for example, settling next to a ridge or in a concave dip. This type of settlement has been well documented for barnacles (e.g. Crisp 1961, Wethey 1984, Chabot \& Bourget 1988, Le Tourneux \& Bourget 1988).

The above processes were repeated using the width of the cyprid at its thickest point (mean width = $0.76 \mathrm{~mm}, \mathrm{SE}=0.0181 \mathrm{~mm}$ ). PSS data from width sym-

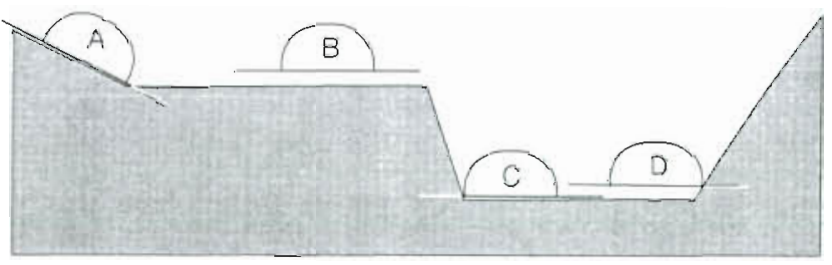

Fig. 2. Diagram showing some of the consequences of the morpho-ethological symbol in relation to surface roughness used to determine the number of potental settling sites (PSS) for the surfaces. Cyprid $A$ and $C$ have settled next to a surface contour feature and thus they each represent 1 PSS, whereas cyprid B cannnot settle as there are no suitable surface features, and cypnd $D$ cannot settle as the position would be too close to cyprid C 
bols will be termed PSS $\max$, the PSS value from length symbols termed $\mathrm{PSS}_{\min }$. A further index was calculated, PSS $_{\text {mid, }}$, which was the mean of PSS max $_{\text {ax }}$ and PS All PSS indices were expressed in the number of PSS sites per $1 \mathrm{~cm}$ of horizontal surface.

Fractal dimensions: Fractal dimensions permit a summary of non-Euclidean description of surface complexity at a variety of scales. Fractal dimensions for profiles were obtained using the image analysis programme Optimas $^{\oplus}$. Images were captured of each slice profile using a Dage MTICCD 72 camera with a 18 to $108 \mathrm{~mm}$ zoom lens. The lighting was adjusted to maximise contrast and the lens adjusted to give a minimum magnification of $25 \times$. The profile-following algorithm in Optimas was used to digitise $-8 \mathrm{~mm}$ of each cast and obtain the profile length in 5 step sizes from 12.5 to $125 \mu \mathrm{m}$. Fractal dimensions for each surface were then determined from Richardson plots (Russ 1994).

Analysis of spatial pattern. From the many methods that have been devised to analyse the spatial pattern of organisms, 2 methods were selected to describe the spatial pattern of settled barnacles over a variety of scales:

Morisita's index of dispersion: Morisita (1962) developed the following index of dispersion $\left(I_{\delta}\right)$ for a set of quadrats:

$$
I_{\delta}=\frac{S\left(\sum n^{2}\right)-N}{N(N-1)}
$$

where: $n=$ total number of individuals in a quadrat; $N=$ total number of all individuals; $S=$ total number of quadrats.

If the value of $I_{\delta}$ is 1 , then the individuals are distributed randomly. Values lower than 1 suggest a more uniform distribution than random, and values greater than 1 suggest an aggregated distribution. Significance is assigned to the $I_{\delta}$ values using a $\chi^{2}$ test with $S-1$ degrees of freedom. The quadrat counts represent the observed data, and the expected data are the quadrat counts assuming a random distribution. $\chi^{2}$ analyses were carried out using Minitab (ver. 10).

Morisita's indices were calculated for the distribution of barnacles with 5 different block sizes: namely, $10 \times$ $10 \mathrm{~mm}, 20 \times 20 \mathrm{~mm}, 35 \times 35 \mathrm{~mm}, 50 \times 50 \mathrm{~mm}$ and $75 \times$ $75 \mathrm{~mm}$. Ten blocks were randomly selected from the $100 \times 100 \mathrm{~mm}$ quadrat and the number of barnacles in the blocks determined using a QBASIC program (written by $T$ D. Stevenson). Morisita's index was calculated from these 10 blocks.

For each of the studied surfaces, Morisita's index was calculated at 4 different densities at each of the block sizes described above. The Morisita's analyses were carried out at approximately even differences in density for each surface (i.e. $1 / 4,1 / 2,3 / 4$ and 1 of total number of settlers); it should be noted that these densities differed between surfaces due to the differences in the total number of settlers. To counteract the problem of multiple $\chi^{2}$ tests for each surface (5 blocks $\times 4$ densities) a Bonferroni adaptation (Manly 1991) was carried out on the significance level of the Morisita's index, reducing the significance to $\mathrm{p}<0.0025$ (i.e. $\mathrm{p}=0.05$; thus 0.05 significance $/ 20$ tests $=0.0025$ ) .

Morisita's index has advantages over many other indices of dispersion in that it is relatively independent of the type of distribution of individuals between quadrats and the size of the mean (Southwood 1971). Although $I_{\delta}$ is a strong function of the number of sampling units (S) at both ends of its range (Elliot 1977), the index was used throughout this study with a constant $S . I_{\delta}$ is also strongly influenced by quadrat size, but only when the distribution of individuals is regular (Elliot 1977).

Nearest neighbour analysis: The use of Morisita's index permitted settlement pattern to be analysed down to a block size of $10 \times 10 \mathrm{~mm}$. If smaller block sizes were used, then, at low densities of barnacles, counts were often too low (i.e. $<5$ ) to permit $\chi^{2}$ tests to be carried out. So, for the analysis of smaller scale interactions between barnacles a nearest neighbour technique was used.

A Monte Carlo test was used to compare the mean nearest neighbour distances for a set of points in a quadrat with the distribution of such distances obtained when points were allocated randomly over the quadrat area. A statistic, $q_{i}$, representing the mean distance between the points and their ith nearest neighbour was calculated with $i=1$ to 10 . The mean $q_{2}$ values were then compared with a set of Monte Carlo simulated $q_{i}$ values in which the same number of points were randomly added to an identically sized block. Statistical significance of the $q_{i}$ values for the data compared with the simulated $q_{i}$ values could be determined by counting the number of simulated $q_{1}$ values that fall above or below the actual $q_{\text {, values. If }}$ the $q_{i}$ value was above or below $95 \%$ (i.e. 950 simulations) of the simulated $q_{i}$ values, then it was considered to be significantly different to random.

Due to the computer-intensive nature of the analysis, only a total of 100 points could be dealt with in any one analysis. Two sets of nearest neighbour analyses were carried out. At low settlement densities of barnacles (0.5 to 1.75 barnacles $\mathrm{cm}^{-2}$ ) a randomly selected block (size $75 \times 75 \mathrm{~mm}$ ) was used, and at the highest barnacle density achieved by each surface ( 5 to 25 barnacles $\mathrm{cm}^{-2}$ ) a block size of $20 \times 20 \mathrm{~mm}$ was used. An inhibition distance around each point was used in the simulations such that settlement could only occur $<1 \mathrm{~mm}$ from the nearest neighbour. Analyses were carried out using the RT computer programme (Manly 1991, 1994). A total of 1000 Monte Carlo simulations were carried out. 


\section{RESULTS}

\section{Densities of potential settlers}

The density of cyprids in the water column decreased over the period of the settlement study (Fig. 3). The number of cyprids per standard tow at 6 tides prior to the start of the settlement experiment was over 30000 ; this decreased sharply to just over 5000 at tide 9 . Less steep declines in the cyprid density were observed over the remaining period of the experiment. At tide 90 no cyprids were delected. These data only give a crude impression of the density of cyprids in the water column due to temporally infrequent sampling. However, during the settlement study an overall decrease in the number of cyprids in the water column was apparent. It is probable that this decline in cyprids represents the tail-end of the settlement season for 1994.

\section{Barnacle settlement densities}

There were large differences between surfaces in the total number of barnacles settled after 75 tides (Table 1). The largest number of barnacles, a total of 2409 (= 24.09 barnacles $\mathrm{cm}^{-2}$ ), settled on the concrete substratum of surface 1 . Conversely, surface 2, enamelled metal, showed no settlement. The remaining surfaces had densities between 6 and 18.5 barnacles $\mathrm{cm}^{-2}$ at the end of the experiment. There was an approxi-

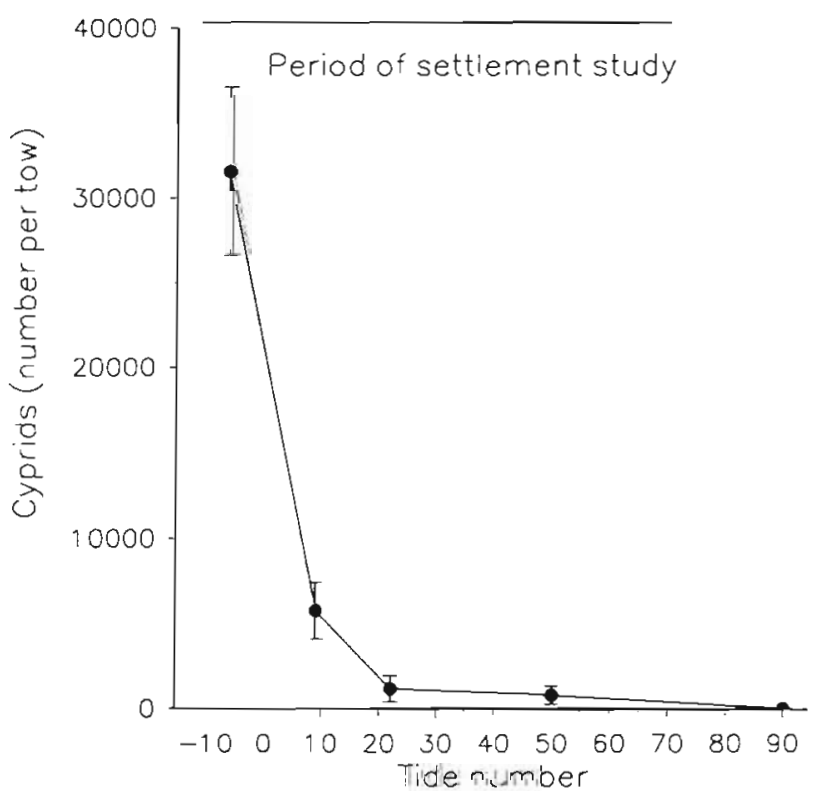

Fig. 3. Number of cyprids caught per standard tow $( \pm 1 \mathrm{SE})$ in the water column before, during, and after the period of the study mately 2 -fold difference in the number of settled barnacles between the 2 concrete surfaces ( 1 and 6 ) and a similar difference between the 2 wood surfaces $(3$ and 5). Such differences in density between similar materials suggests that factors other than those related to the type of material were determining barnacle settlement density. These other factors were operating at a scale less than the maximum distance $(-2 \mathrm{~m})$ between the pairs of surfaces.

Cumulative frequency plots of barnacle settlement approximated to a sigmoid curve, with settlement initially slow then increasing from about tide 20 to high levels of settlement at about tide 60 , then slowing down again during the last few tides (Fig. 4). It could be argued that the slowing down of settlement at high densities is evidence for density-dependent settlement; however, it could also be related to the decline in the number of cyprids in the water column towards the end of the experimental period (Fig. 3).

To quantify the magnitude of the difference between cumulative settlement between the surfaces, regression equations were used to predict the tide at which $50 \%$ of the barnacles had settled. Regression equations predicting cumulative settlement by tide number were calculated using arcsine transformed data. To reduce the effect of the lag phase prior to the maximal rate of settlement, surfaces with $<0.1$ barnacles $\mathrm{cm}^{-2}$ were removed from the analysis. All regressions were highly significant $(p<0.0001)$. The tide at $50 \%$ settlement varied between tide number 23 (surface 1) and tide number 44 (surface 5) (Table 1).

\section{Settler density relationships to surface roughness}

From height measurements taken at $0.75 \mathrm{~mm}$ intervals, from the photo mosaic, along the length of each profile, a diagram of surface contour was constructed (Fig. 5). At a small scale a similar diagram of surface texture was constructed from the data collected from the image analysis profile (Fig. 6)

At the small spatial scale, the regression line between step size and distance travelled (Richardson plot), from which the fractal dimension $(D)$ was determined, was significant $(p<0.05)$ for 3 of the 7 surfaces studied (surface 1, $D=1.05, \mathrm{p}<0.05$; surface $2, D=$ 1.03, $\mathrm{p}<0.05$; surface $4, D=1.01, \mathrm{p}<0.05)$. However, the fractal dimensions of these lines were not significantly different $(p>0.05)$ from the Euclidean dimension of 1 (Russ 1994). From these results it would appear that, for the range of surfaces studied, the surfaces were Euclidean and not fractal

Regression analysis predicting the final density of barnacles using ISO number, PSS min. PSS $_{\max }$ and PS mid $_{\text {mid }}$ is given in Table 2. PSS mid was used to represent a 

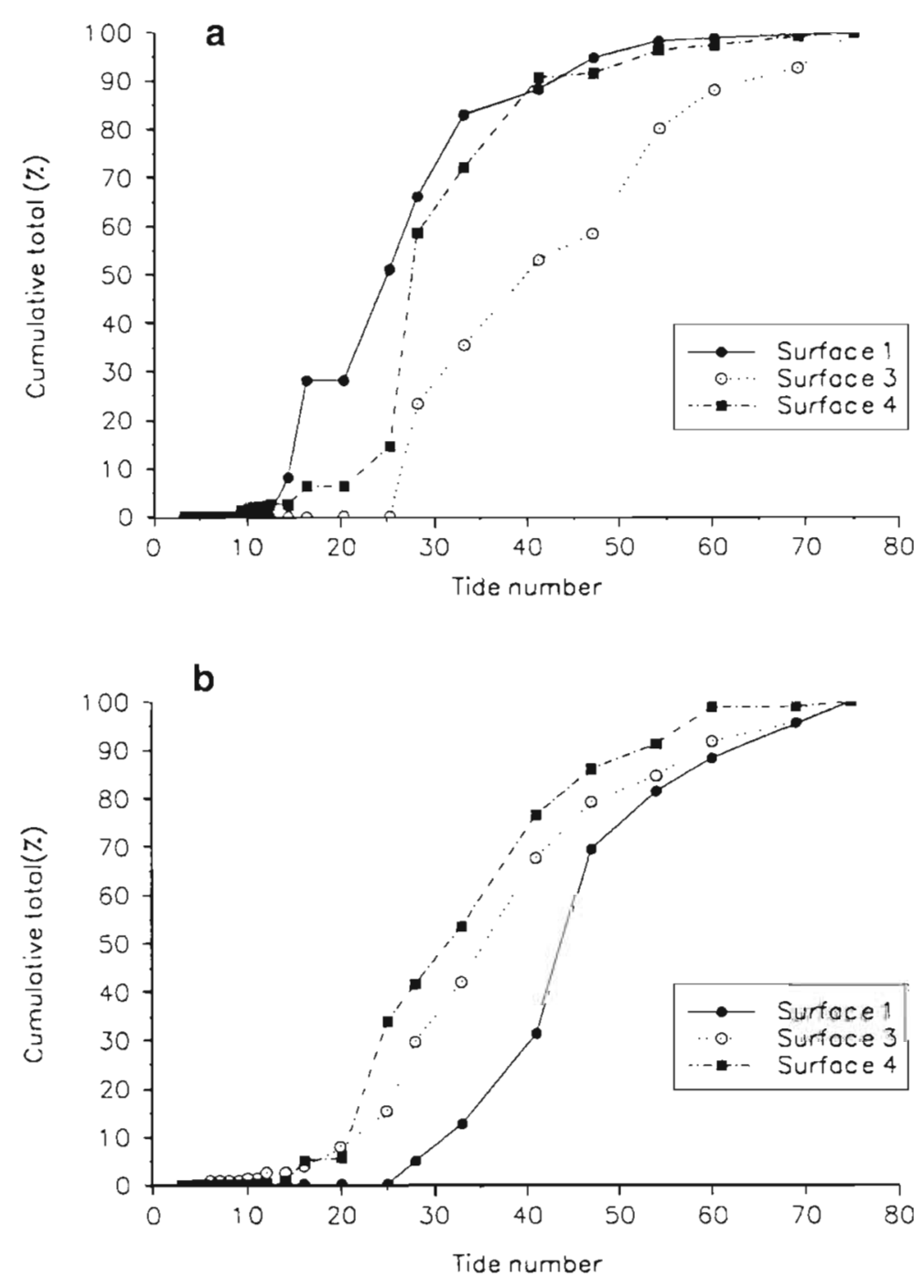

Fig. 4. Cumulative frequency plots of the settlement of Semibalanus balanoides over the 75 tides of the study. (a) Surfaces 1,3, and 4; (b) Surfaces 5 to 7 cant Morisita's indices (surfaces 1, 2, 3, 5, and 6 , Fig. 8). If $I_{\delta}$ for a particular block size/density was not significantly different $(p<0.001$, Bonferroni adaptation enforced) from a random distribution, then the index was plotted as 1. Surfaces 4 (rusty metal) and 7 (sandstone) were not distributed significantly different from random for any combination of block size and density. None of the studied surfaces exhibited any degree of uniform distribution (Morisita's index $<1$ ); however, significant aggregations were found on a majority of the surfaces. Surface 1 (Fig. 8) showed a strongly aggregated distribution at densities up to $\sim 8$ barnacles $\mathrm{cm}^{-2}$ at all block sizes and also displayed some aggregation at $\leq 30 \times$ $30 \mathrm{~mm}$ block size over a range of densities up to 24 barnacles $\mathrm{cm}^{-2}$. Surface 3 showed an aggregated distribution at densities up to 4 barnacles $\mathrm{cm}^{-2}$ with small $(\leq 45 \times 45$ $\mathrm{mm}$ ) block sizes. Surface 5 was similar to surface 1, with strong aggregations up to approximately 5 barnacles $\mathrm{cm}^{-2}$ at all block sizes and aggregation at higher densities (up to 10 barnacles $\mathrm{cm}^{-2}$ ) at small ( $\leq 30 \times$ $30 \mathrm{~mm}$ ) block sizes. Finally, surface 6 was only aggregated at sinall $(\leq 30 \times 30 \mathrm{~mm}$ ) block sizes at a range of densities up to 10 barnacles $\mathrm{cm}^{-2}$.

\section{Nearest neighbour analysis}

Nearest neighbour analysis was used to examine interactions between barnacles at scales $\leq 10 \mathrm{~mm}$. The results from the low density analysis are graphically presented in Fig. 9. A majority of the mean value allowing for orientation of the cyprids - it assumes that half orientate lengthways and half sideways to the profile direction. The ISO number and PSS $_{\max }$ were not significantly related to settler density. Conversely, PSS $_{\min }$ and PSS $_{\text {mid }}$ could significantly predict the number of settlers. The strongest relationship was between PSS $_{\min }$ and density [Settler density = $\left(5.68 \times\right.$ PSS $\left._{\min }\right)-4.16, \mathrm{p}<0.01$, Fig. 7]

\section{Spatial patterns of barnacle settlement}

\section{Morisita's index}

The change in Morisita's index by block size and density was plotted for each surface that had signifi- nearest neighbours were significantly closer than predicted from random simulations. If a nearest neigh-

Table 2. Regression equations predicting settler density from surface profile indices. ISO: measure of surface relief; PSS $_{\min }$ : potential settling site (PSS) data from width symbols; PSS $_{\max }$ : PSS data from length symbols; PSS $_{\text {mid }}$ : mean of PSS $S_{\max }$ and PSS $_{\text {min. }}$ ns: not significant

\begin{tabular}{|lcc|}
\hline Profile index & Regression equation & Significance \\
\hline ISO & - & $\mathrm{ns}$ \\
$\mathrm{PSS}_{\min }$ & $\left(5.68 \times \mathrm{PSS}_{\min }\right)-4.16$ & $\mathrm{p}<0.01$ \\
$\mathrm{PSS}_{\max }$ & - & $\mathrm{ns}$ \\
PSS $_{\operatorname{mid}}$ & $\left(4.34 \times \mathrm{PSS}_{\operatorname{mid}}\right)-2.16$ & $\mathrm{p}<0.05$ \\
\hline
\end{tabular}




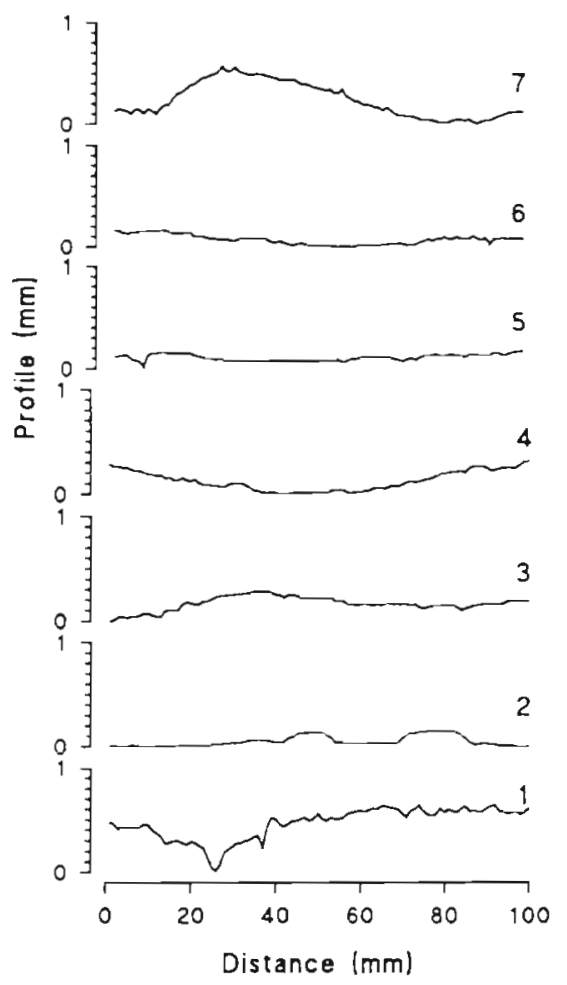

Fig. 5. Surface contour of the 7 surfaces determined from the photomosaic

bour was significantly closer than simulated, this means that the barnacles were settling in an aggregated pattern in relation to conspecifics. The mean first nearest neighbour on all the surfaces was significantly closer than the simulated value by between 1 and $2 \mathrm{~mm}$. The mean first 10 nearest neighbours were significantly closer than the simulated values for surfaces 1,5 and 6 . These data give strong evidence for gregarious settlement in relation to conspecifics. The mean values of the 2 nd to 10 th nearest neighbour on surface 3 and the 3 rd to 10 th on surface 4 were not different from simulated random settlement. This suggests that these barnacles were settling gregariously to the closest conspecific, but not to the more distant barnacles. Surface 7 had significantly aggregated settlement of the first 5 nearest neighbours; however, at nearest neighbours 9 and 10 the simulated values were lower than the actual data, suggesting an over-dispersed pattern in settlement.

From the results of the nearest neighbour analysis at higher densities ( 5 to 25 barnacles $\mathrm{cm}^{-2}$ ) only the first nearest neighbour on surface $1\left(23.5 \mathrm{~cm}^{-2}\right)$ was found to be significantly aggregated $(\mathrm{p}<0.001)$. Thus, it can be concluded that for barnacle settlement at high densities the spatial pattern was generally random, overdispersion was not found on any surface.

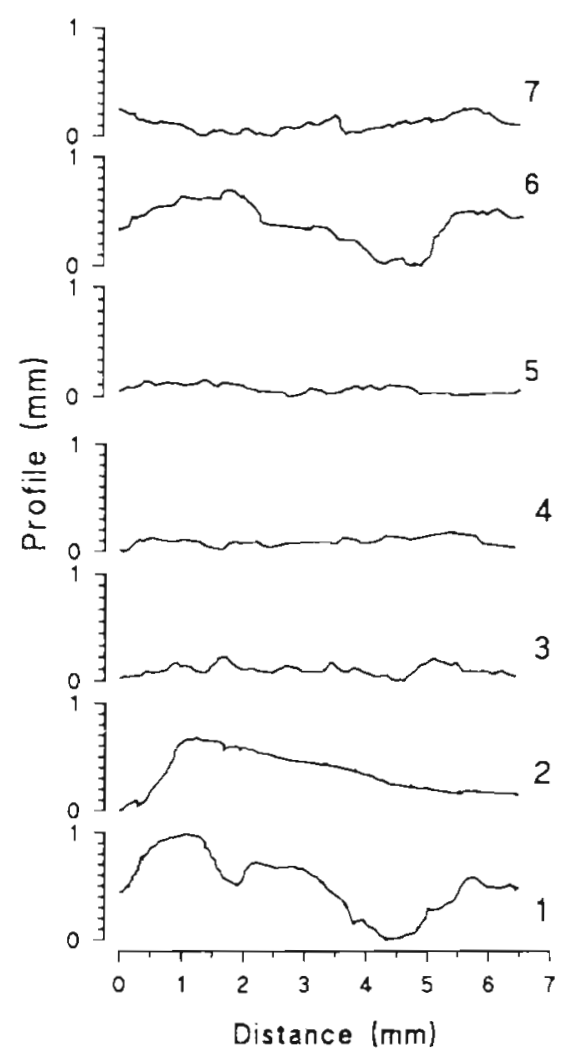

Fig 6. Surface texture of the 7 surfaces determined from image analysis measured over $6.5 \mathrm{~mm}$

\section{DISCUSSION}

\section{Gregariousness and founder members}

During the first 20 tides the number of cyprids in the water column was relatively high; however, the number of barnacles settling on the studied surfaces was relatively low. The surfaces thus appeared to have changed from being relatively undesirable sites to desirable settlement sites after tide 20 . Two possible changes in surface characteristics could have been either the settlement of the first few barnacles promoting gregarious settlement of conspecifics or the development of a microbial biofilm promoting cyprid settlement.

Preferential gregarious settlement by conspecifics has been documented for a variety of barnacle species including Semibalanus balanoides (Knight-Jones 1953). Gregarious settlement is a strategy to ensure sexual reproduction involving non-reciprocal sperm transfer during copulation (Anderson 1994).

It can be argued that the lack of potential for gregarious settlement in the early stage of settlement of a surface is a reason for low settlement over the first 20 tides. The active non-gregarious settling of the early 


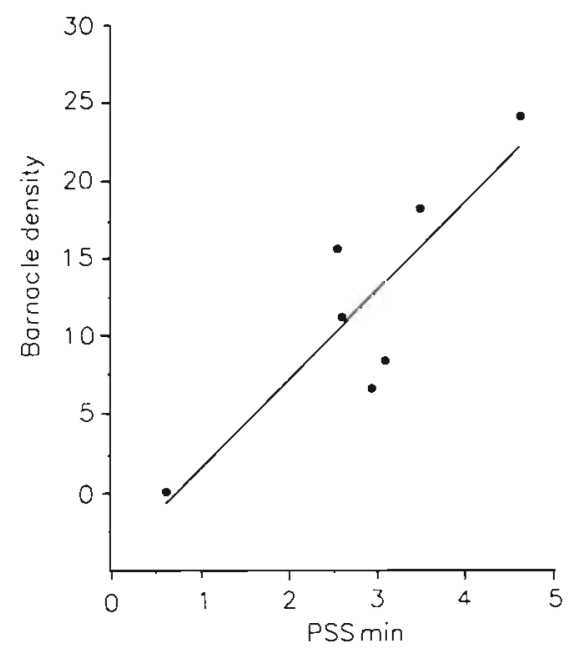

Fig. 7. Relationship between the density of Semibalanus balanoides settlement $\left(\mathrm{cm}^{-2}\right)$ after 75 tides and the number of potential settling sites ( PSS $_{\min }$ )

a) surface 1

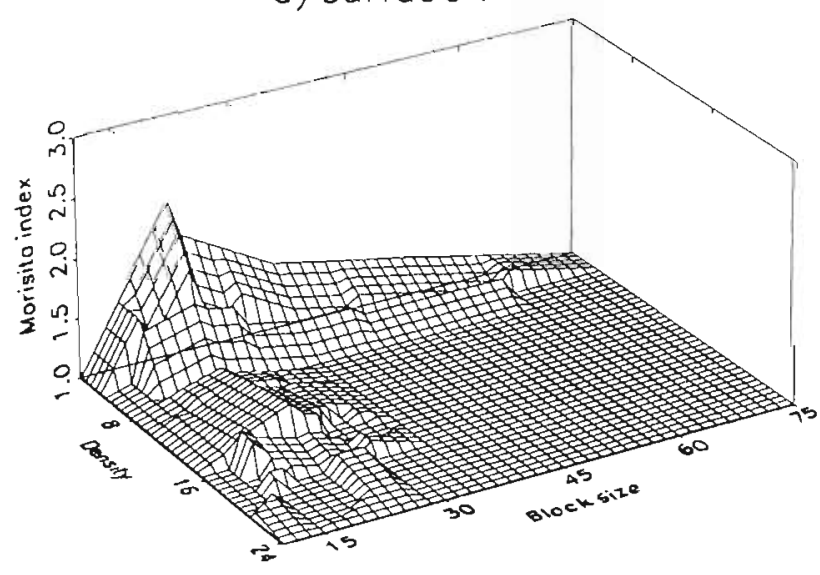

c) surface 5

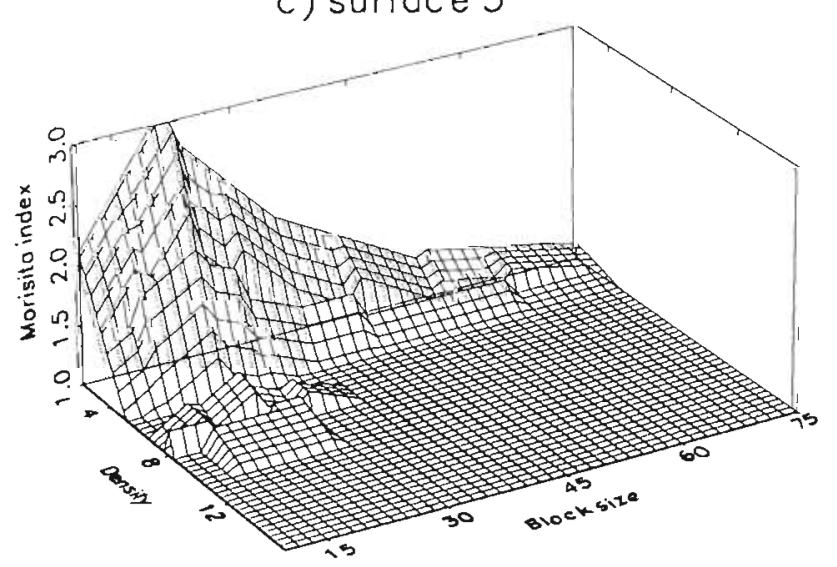

colonisers suggests a different set of cues determining the colonisation decision being made by the founder individual. Two types of settlers, gregarious settlers (which respond primarily to conspecifics) and founders (which respond to biofilms with no conspecifics), have been found in larval females of a sedentary polychaete, Hydroides dianthus (Toonen \& Pawlik 1994). Thus it is possible that the presence of a small number of a distinct sub-population of founder cyprids was causing initial low density settlement on unoccupied surfaces. Further experimental evidence is required to test this hypothesis.

Some marine invertebrates, such as Spirorbis sp. (Henschel \& Cook 1990) and the ascidian Ciona intestinalis (Szewzyk et al. 1991), tend to settle preferentially on microbial biofilms. The development of a biofilm on a de novo surface would take a number of days, thus causing a lag in cyprid settlement; however, the role of the biofilm for cyprid settlement is not
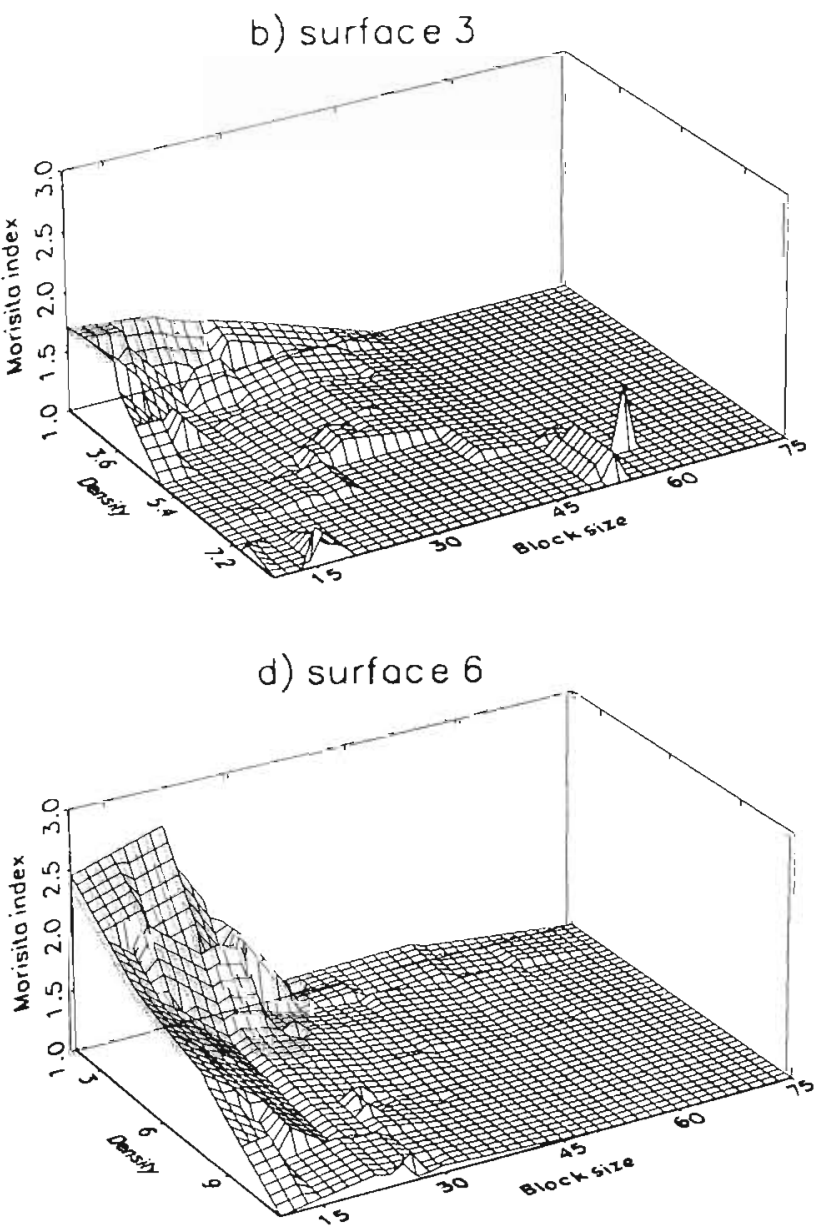

Fig. 8. Spatial pattern of the settled Semibalanus balanoides measured by Morisita's index related to density of settlement $\left(\mathrm{cm}^{-2}\right)$ and block size (mm) used to calculate Morisita's index. Morisita index value 1 = random pattern; Morisita index values plotted above 1 represent a significant $(p<0.00025)$ aggregation. Note the varying settlement density values on the $z$-axis 
fully understood. Biofilms have been shown to be unimportant to cyprid settlement (e.g. Notomegabalanus algicola, Henschel \& Cook 1990) or to inhibit settlement (e.g. Balanus amphitrite, Maki et al. 1988), or to have both an inhibitory and stimulatory effect on Elminius modestus cyprid settlement, dependent on biofilm age (Neal \& Yule 1994)

Reasons for the variation in the proportions of barnacles settling over a particular period being variable between the surfaces were not clear, but could be related to a number of features such as local hydrodynamic differences. It was probable that the surfaces which filled up more quickly with barnacles were the surfaces which were more preferable for barnacle settlement and which had a greater density. However, a Spearman's rank correlation was carried out between the tide number at which $50 \%$ of the barnacles had settled and the total number of barnacles which settled on the surfaces after 75 tides. The correlation was not significant $(\mathrm{r}=-0.17, \mathrm{n}=6)$. This result suggests that the surfaces studied were settled at different proportional rates and that these rates were not related to the density after 75 tides.
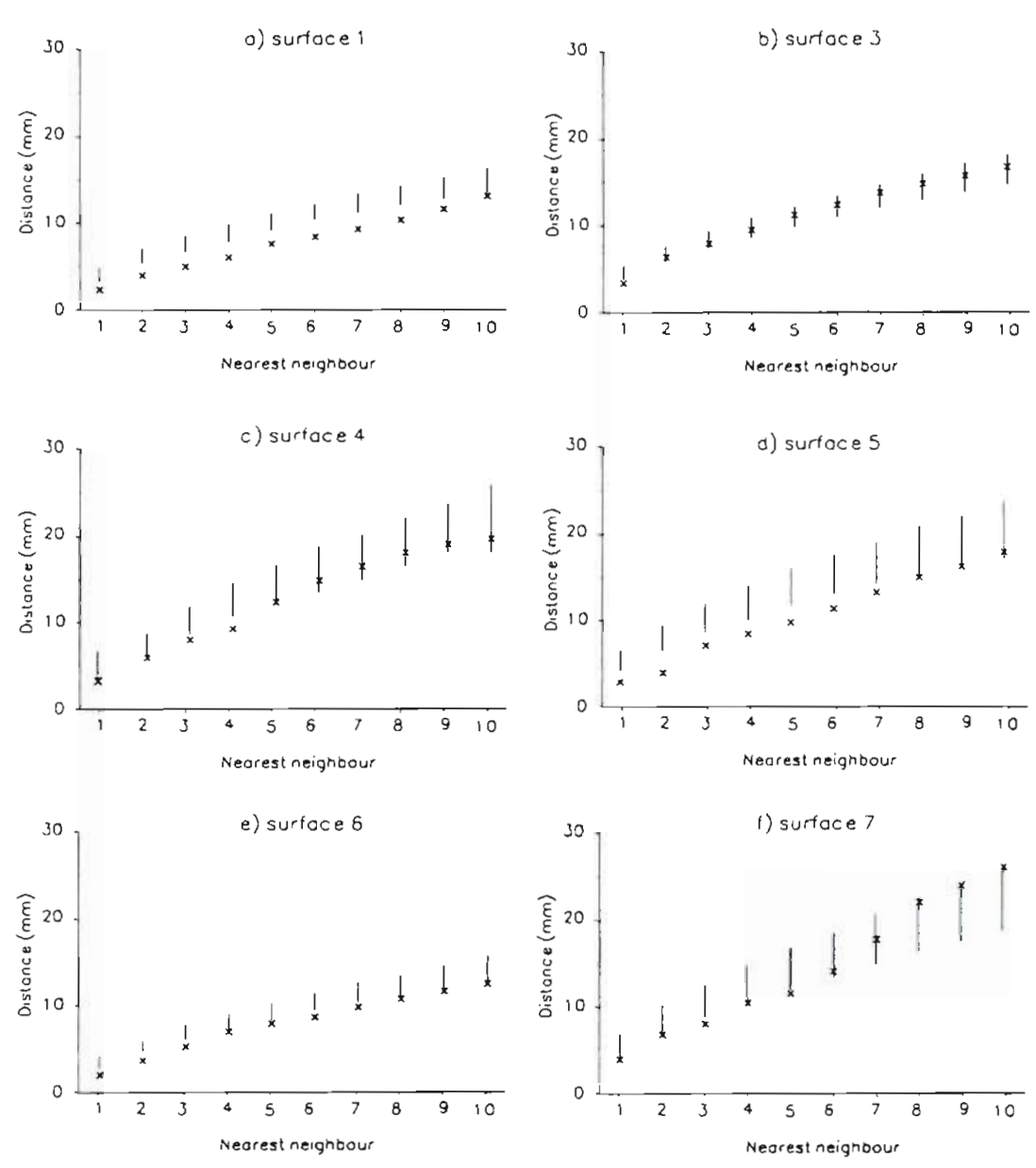

Fig. 9. Mean nearest neighbour distance (mm) for the first 10 nearest neighbours $\left(q_{1 \ldots 10}\right)$ at low density settlement, with the measured data represented by ' $x$ ' and the Monte Carlo simulation data maximum and minimum represented by vertical lines

\section{Surface roughness and cyprid settlement}

Much work on the effect of texture on settling organisms has been carried out; however, quantification of surface contour and texture has been relatively uncommon. This can be attributed to the fact that a surface is a complex 3-dimensional structure which has variation at many scales. Two general approaches to the study of surface texture can be found in the literature: (1) Categorical descriptions of surface roughness. For example, Raimondi (1990) and Johnson (1994) used the terms 'rough' and 'smooth' to compare surfaces. Alternatively, Harlin \& Lindebergh (1977) used experimental surfaces constructed from 3 grades or categories of particles. (2) Simplification of the surface in to a few relatively simple features. For example, Crisp (1961), Wethey (1984), Chabot \& Bourget (1988), and Bourget et al. (1994) used pits, cracks, and crevices in otherwise smooth surfaces to examine cyprid settlement.
Recent developments including the general availability of image-analysis systems and developments in surface analysis techniques, for example the development of fractal geometry (Mandlebrot 1977, Hastings \& Suigihara 1993) and measures of potentially available space (Sanson et al. 1995), have permitted easier quantification of the complexity of natural substratum. Fractal dimensions have been used successfully for the description of the complexity of vegetation in relation to arthropod body lengths (Morse et al. 1985) and of metazoan community structure in relation to marine macroalgae (Gee \& Warwick 1994), Jeffries (1993) found that the numbers of invertebrate taxa, individuals and numbers of some species increased with increased fractal dimension of constructed pond weeds, but he noted that: 'how the variation in complexity causes differences in numbers is not clear and individual taxa probably respond to different factors'. This represents an important point, because, although the fractal dimension might represent an overall mea- 
sure of a habitat to which the community may respond in terms of an individual or a species within that habitat it would probably not respond to the fractal dimension but to some part (i.e. scale) of it.

Le Tourneux \& Bourget (1988) compared the fractal dimension of a transect of attachment sites of Semibalanus balanoides cyprids to the fractal dimension of a transect either side of the attachment zone. The authors concluded that at step sizes between 0 and $35 \mu \mathrm{m}$, the attachment site tended to have a greater fractal dimension than the neighbourhood zone (paired $t$-test, $\mathrm{p}<0.05$ ).

A number of problems can be identified with this approach. Firstly, multiple $t$-tests were used in the analysis and construction of the scale of observation against significance level curves; thus, for example, a Bonferroni adaptation for multiple tests could have been carried out. If this procedure was adopted, a significance value considerably lower than $\mathrm{p}<0.05$ would be used, and this would bring into question the significant difference between the attachment zone and the neighbourhood area. It was clear that the magnitude of the difference in fractal dimensions between the settled sites was small, for example, at $25 \mu \mathrm{m}$ the attachment zone had a mean fractal dimension of 1.17, whereas the surrounding site had a dimension of 1.13. Secondly, fractal dimensions should have been obtained starting from different positions on the surface (Suigihara \& May 1990). Hence, the increased complexity detected at the smaller scales could be due to a single feature, such as a pit, and not represent increased heterogeneity over the whole of the attachment area. Thus a scaleindependent standard surface measure such as an ISO number would differ markedly between the attachment sites and surrounding zone, and if cyprids were generally settling in pits, then the difference in fractal dimensions between the attachment sites and surrounding areas could be a co-correlate of the presence or absence of pits.

In the range of surfaces studied in this study it was found that surface profiles were not fractal; they were either not significantly different to a Euclidean dimension, or fractal scaling laws were not statistically significant. Thus, it would appear from these results that fractal dimensions at this scale were unimportant at describing differences between barnacle settlement on the surfaces.

\section{Biological indices of surface structure}

The potential for the use of quantitative indices of surface complexity representing known biological/ ecological phenomena, rather than purely mathemati- cally derived indices, has not been greatly tested. Sanson et al. (1995) describe a technique for determining the roughness of a surface in terms of the numbers and sizes of refuges on the surface. The similarly biological-based approach of this study was used in the assessment of PSS. All 3 PSS indices, in particular PSS $_{\min }$, were significantly related to the density of settlers. Although PSS is a measure of surface roughness, it is neither a measure of surface contour (scale of observation greater than the size of the organism) or surface texture (scale of observation smaller than the size of the organism). A new term needs to be introduced to identify the scale of surface roughness that PSS values represent, namely, surface affinity. Surface affinity is defined as a measure of the roughness of the surface measured at the same scale as the organism to which it relates.

Two problems can be identified in the approach to measuring surface affinity using PSS. Firstly, the method in its present form can only be carried out in 2 dimensions. This has also been a problem with the measurement of fractal dimensions (Russ 1994) and the potential habitat space technique (Sanson et al. 1995). Sanson et al. (1995) note that the potential habitat technique could be extended to 3 dimensions, though this would involve technical difficulties; however, they argue that ecologists need a method for quantifying surface roughness objectively and comparably and do not necessarily require 3 dimensions. Similar arguments could be applied to the measurement of surface affinity using PSS.

A second problem with the PSS technique is that it was not clear if cyprids were actually settling on PSS, though from the results from previous work (e.g. Crisp 1961, Wethey 1984) it is apparent that the PSS should represent actual settling sites. A more useful test of the PSS index would be to look at the precise settling position of cyprids on a complex natural surface and determine if cyprids tended to settle on PSS. If cyprids were responding to PSS, then this would permit the testing of the relationship between suitable settling sites (SSS) and density. Raimondi (1990) suggested that when settlement density was high, differences between locations reflected difference in the number of SSS; however, settlement densities would be similar among sites at lower densities as SSS would not be limiting.

This study has shown that for Semibalanus balanoides settling on a number of natural surfaces a biologically orientated measure of surface affinity was related to the density of settlers. Although many studies have shown preferential settlement in pits and crevices, this study represents one of the first attempts to relate the density of settled barnacles to surface features for a number of complex surfaces. 


\section{Settlement patterns}

From the results presented in this study it can be concluded that the spatial pattern of recently settled barnacles was a consequence of the density of settlers, the scale at which they were observed and some other factor(s) varying between the surfaces. From these data it was apparent that the spatial pattern of barnacles varied from strongly aggregated to random; this variation related to settlement density and the spatial scale of the analysis. However, there were similarities between the aggregated settlements on the surfaces.

The strongest aggregations were found at approximately block size $30 \times 30 \mathrm{~mm}$ at low densities $(\leq 8 \mathrm{bar}$ nacles $\mathrm{cm}^{-2}$ ). The strong aggregation at block size $30 \times$ $30 \mathrm{~mm}$ became less apparent at densities $>8$ barnacles $\mathrm{cm}^{-2}$. In terms of densities of barnacles settled on the surface this means that at block size $30 \times 30 \mathrm{~mm}$ there are greater density differences between a set of random quadrats than at smaller or greater block sizes.

Mullineaux \& Butman (1991) showed that, for Balanus amphitrite cyprids settling in flow regimes, the net excursion of cyprids was generally within $3 \mathrm{~cm}$ after contact with the substratum. Semibalanus balanoides cyprids have been found to exhibit a similar scale of exploration of the neighbourhood at a similar scale (Crisp 1961) as well as gregarious settlement in relation to conspecifics (Knight-Jones 1954). These results suggest that, if barnacles range over the scale of approximately $3 \mathrm{~cm}$ and do not find conspecifics, they will tend to move on. However, if conspecifics are found, then settlement in that region will tend to occur. Thus at low densities a patchy distribution of barnacles could arise with aggregations of conspecifics and areas with little or no settlement. The scale of this patchiness would be determined by the scale of cyprid exploration behaviour. If $S$. balanoides exploration behaviour was on a scale similar to that of $B$. amphitrite, then the patchiness would be expected at a scale of $\sim 3 \mathrm{~cm}$, akin to the block size of $30 \times 30 \mathrm{~mm}$. These results could suggest that the scale of the strongest aggregation was a consequence of the surface exploration behaviour of the S. balanoides cyprid.

Satchell \& Farrell (1993) found, using nearest neighbour techniques, that 3 balanomorph species (Balanus amphitrite, B. glandula, and Chthamalus dalli) settled randomly over a range of densities. The data presented here on another balanomorph species (Semibalanus balanoides) has shown that aggregation tends to be found at low densities $\left(<8 \mathrm{~cm}^{-2}\right)$ with settlement becoming random at higher densities. Reasons for the settling patterns of the balanomorph species studied by Satchell \& Farrell (1993) observed in the field were not clear.
The settlement patterns identified in this study can be explained by the biology of Semibalanus balanoides. At low densities barnacles have to settle gregariously for sexual reproduction to occur at a later date; thus low density aggregated settlement could be related to the requirement for mates during the breeding process. Aggregated settlement at higher densities will tend to lead to increased competition for space; thus the avoidance of aggregated settlement at higher densities could potentially be an intra-specific competition avoidance technique and consequently of importance for survival.

\section{CONCLUSIONS}

The lag phase prior to heavy settlement could have been caused by either the necessity for gregarious settiing or by microbial film development. Proportional rates of settlement were different between surfaces and were not related to final settlement densities. Barnacle settlement was not related to a standard measure of surface roughness or to fractal dimension but to a biological index of surface affinity (PSS). Settlement pattern was found to vary with settlement density and spatial scale of analysis. Aggregated settlement at low densities could be related to the requirement to find a mate in close proximity, whereas avoidance of aggregated settlement by Semibalanus balanoides at higher densities could potentially be an intra-specific competition avoidance technique.

Acknowledgements. The authors thank Tom Stevenson and Prof. John Davenport for helpful discussions on this work, Dr J. J. Thomason (Ontario Veterinary College, University Guelph, Canada) for carrying out the image analysis work, Wil Conn (Dept. of Applied Sciences, University of the West of England, UK) for production of the surface photomosaic and Peter Winn-Brown (Dept. of Zoology, University of Sheffield. UK) for digitising barnacle settlement. J.M.H. was supported by the Sheina Marshall Fellowship and The Royal Society.

\section{LITERATURE CITED}

Anderson DT (1994) Barnacles: structure, function, development and evolution. Chapman \& Hall, London

Bingham BL (1992) Life histories in an epifaunal community coupling of adult and larval processes. Ecology 73: 2244-2259

Bourget E, DeGuise J, Daigle G (1994) Scales of substratum heterogeneity, structural complexity, and the early establishment of a marine epibenthic community. J Exp Mar Biol Ecol 181:31-51

Chabot R, Bourget $E$ (1988) Influence of substratum heterogeneity and settled barnacle density on the settlement of cypris larvae. Mar Biol 97:45-56

Crisp DJ (1961) Territorial behaviour in barnacle settlement. J Exp Biol 38:429-446 
Crisp DJ, Barnes $\mathrm{H}$ (1954) The orientation and distribution of barnacles at settlement with particular reference to surface contour. J Anim Ecol 23:142-62

Crisp DJ, Meadows PS (1962) The chemical basis of gregariouness in cirripedes. Proc R Soc Lond Ser B Biol Sci 156: $500-520$

Dineen JF, Hines AH (1994) Effects of salinity and adult extract on settlement of the oligohaline barnacle Balanus subalbidus. Mar Biol 119:423-430

Elliot JM (1977) Some methods for the statistical analysis of samples of benthic invertebrates. Freshwater Biological Association, Ambleside

Gaines S, Brown S, Roughgarden J (1985) Spatial variation in larval concentrations as a cause of spatial variation in settlement for the barnacle. Balanus glandula. Oecologia 67 . $267-272$

Gee JM, Warwick RM (1994) Metazoan community structure in relation to the fractal dimension of marine macroalge. Mar Ecol Prog Ser 103:141-150

Harlin MM, Lindebergh JM (1977) Selection of substratum by seaweeds: optimal surface relief. Mar Biol 40:33-40

Hastings HM, Suigihara G (1993) Fractals: a user's guide for the natural sciences. Oxford University Press, Oxford

Henchel JR, Cook PA (1990) The development of a marine fouling community in relation to the primary film of microorganisms. Biofouling 2:1-11

Hurlburt CJ (1991) Community recruitment: settlement and juvenile survival of seven co-occuring species of sessile marine invertebrates. Mar Biol 109:507-515

Jeffries $M$ (1993) Invertebrate colonization of artificial pondweeds of differing fractal dimension. Oikos 67:142-148

Johnson LE (1994) Enhanced settlement on microtopographical high points by the intertidal red algae Halosaccion glandiforme. Limnol Oceanogr 39:1893-1902

Knight-Jones EW (1953) Laboratory experiments on gregariousness during settling in Balanus balanoides and other barnacles. J Exp Biol 30:584-599

Knight-Jones EW (1955) The gregarious setting reaction of barnacles as a measure of systematic affinity. Nature 175 : 266

Knight-Jones EW, Crisp DJ (1953) Gregariousness in barnacles in relation to the fouling of ships and to antifouling research. Nature 171:1109-1110

Kon-ya K, Miki W (1994) Effects of environmental factors on larval settlement of the barnacle Balanus amphritrite reared in the laboratory. Fish Sci Tokyo 60: 563-565

Larman VN, Gabbot PA (1975) Settlement of cyprid larvae of Balanus balanoides and Elminius modestus induced by extracts of adult barnacles and other animals. J Mar Biol Ass UK 55:183-190

Le Tourneux F, Bourget E (1988) Importance of physical and biological settlement cues used at different spatial scales by the larvae of Semibalanus balanoides. Mar Biol 97 : $57-66$

This article was submitted to the editor
Maki JS, Rittschof D, Costlow JD, Mitchell R (1988) Inhibition of attachment of larval barnacles, Balanus amphritrite, by bacterial surface films. Mar Biol 97:199-206

Mandlebrot BB (1977) Fractals: form, chance and dimension. Freeman, San Fransisco.

Manly BFJ (1991) Randomization and Monte Carlo methods in biology. Chapman \& Hall, London

Manly BFJ (1994) RT a program for randomization testing. Version $1.02 \mathrm{C}$. University of Otago, Dunedin

Marrs SJ, Thomason JC, Cowling MJ, Hodgkiess T (1995) A replica method for the study of marine biofilms. J Mar Biol Ass UK 75:759-762

Minichinton TE, Scheibling RE (1993) Free space availability and larval substratum selection as determinants of barnacle population structure in a developing rocky intertidal community. Mar Ecol Prog Ser 95:233-244

Morisita $M(1962) I_{\delta}$-index, a measure of dispersion of individuals. Res Popul Ecol (Kyoto) 4:1-7

Morse DR, Lawton JH, Dodson MM, Williamson MH (1985) Fractal dimension of vegetation and the distribution of arthropod body lengths. Nature 314:731-733

Mullineaux LS, Butman CA (1991) Initial contact, exploration and attachment of barnacle (Balanus amphitrite) cyprids settling in a flow. Mar Biol 110:93-103

Neal AL, Yule AB (1994) The interaction between Elminius modestus Darwin cyprids and biofilms of Deleya marina NCMB1877. J Exp Mar Biol Ecol 176:127-139

Pineda J (1994) Spatial and temporal patterns in barnacle settlement rate along a southern California rocky shore. Mar Ecol Prog Ser 107:125-138

Raimondi PT (1990) Patterns, mechanisms, consequences of variability in settlement and recruitment of an intertidal barnacle. Ecol Monogr 60:283-309

Russ JC (1994) Fractal surfaces. Plenum Press, London

Sanson GD, Stolk R, Downes BJ (1995) A new method for characterizing surface roughness and available space in biological systems. Funct Ecol 9:127-135

Satchell ER, Farrell TM (1993) Effects of settlement density on spatial arrangement in four intertidal barnacles. Mar Biol 116:241-245

Southwood TRE (1971) Ecological methods. Chapman \& Hall, London

Suigihara G, May RM (1990) Applications of fractals in ecology. Trends Ecol Evol 5:79-86

Szewzyk U, Holmstrom M, Wrangstadhl MO, Samuelsson MO, Maki JS, Kjelleberg S (1991) Relevance of the exopolysaccharide of marine Pseudomonas strain $\$ 9$ for the attachment of Ciona intestinalis larvae. Mar Ecol Prog Ser 75:259-265

Toonen RJ, Pawlik JR (1994) Foundations of gregariousness. Nature 370:511-512

Wethey DS (1984) Spatia] pattern in barnacle settlement: day to day changes during the settlement season. J Mar Biol Ass UK 64:687-698

Manuscript first received: February 13, 1996

Revised version accepted: March 25, 1996 